More Information

\title{
Galenic hospital laboratory during COVID-19 emergency: A practical experience in an advanced country
}

\author{
Fiazza C ${ }^{1}$, Ferraiuolo $\mathrm{A}^{2}$, Luisetto $\mathrm{M}^{3 *}$ and Ram Sahu ${ }^{4}$ \\ ${ }^{1}$ Medical Pharmacologist, Hospital Pharmacist Manager, Pharmaceutical Department, PC Area Hosp \\ 29121, Italy \\ ${ }^{2}$ Pharmacist, Master, Pharmaceutical and Regulatory Strategies, Medicinal Products Development, \\ Parma, Italy \\ ${ }^{3}$ Applied Pharmacologist, Hospital Pharmacist Manager, 29121 PC Area Hosp, Italy \\ ${ }^{4}$ Department of Pharmaceutical Science, Assam University, Silchar, Assam, 788011, India
}

\section{Abstract}

In the actual COVID-19 emergency, as pandemic disease, in many countries at the same time there was the rapid need to use preventive and therapeutic measures to control the diffusion of infection.

In PC AREA (Italy north) in the period between March and May 2020, in fact, were observed about 1000 deaths related to COVID-19 (in march $2020+271 \%$ death vs 2019). Between all the measure submitted by public international institution like WHO, OMS, CDC and many other, the deeply use of disinfectants product became a crucial fact in safety procedure and protocols. The high amount of this disinfectants and antiseptic was needed especially in hospital settings or assimilates structure (named as COVID-19 hospital) but also for territorial healthcare need. So it was needed to buy from industries this product but also to start an internal production in galenic laboratories. This because pharmaceutical industries not provided in some cases the request amount of this "'safe life products. In this work is reported a practical experience in a public hospital, Pc AREA related GALENIC extra -ORDINARY PRODUCTION of disinfectants and antispetics. The result of this local experience experience can be easily translated to other countries in the world (advanced or also not advanced).

\section{Introduction}

In the period observed, starting from February to March, Italy was deeply interested by COVID-19 PANDEMIA like other countries in the world. This created a real NEW complex situation for the hospital organization dues to the need to treat an high amount of patient in alimited periods of time and related to a limited industry production availability. In the same time in fact many hospitals required high amount of disinfectants and antiseptic. To prevent the diffusion and spread of Coronavirus - COVID-19 many measures were proposed by public national and international health organizations like WHO, CDC, OMS, ministry of health and so on.

Measures adopted also by italian ministry of health. (from lockdown, to social distancing, to musks use, to diagnostic test, medical devises as individual protective dispositive and many other since strictly use of antiseptic and disinfectant for hands and closed environment and related sanification need). This severe disease was characterized by high diffusivity and high mortality rate especially in some world region. (see for example WU- HAN, north Italy et other). But not in all countries was seen the same mortality rate: it was related to the different kind of measure adopted (5). Between the various public health measures adopted to prevent diffusion of this severe disease one of the most important were the antiseptic and disinfectant policy. Disinfectants to treat environment and antiseptics for patients and healthcare professional. Antiseptics were also used to clean and disinfect hands in public places like train -station, metro, office, and any other situation.

All the measures adopted like mask use, social distance, Lockdown, disinfectant use, informatic tracement Diagnostics, individual protective products and many other produced a reduction of RT (CONTAJOUS INDEX). The high distribution of 
the disease IN THE POPULATION required in short time a lot of amount of all these products and measures. Hospitals and institutions needed to get this products from pharmaceutical industry but the high level of requests by many hospitals in the same time created a situation of lack of product. In this situation there was the need to auto-product the disinfectants in a galenic lab Figures 1,2.

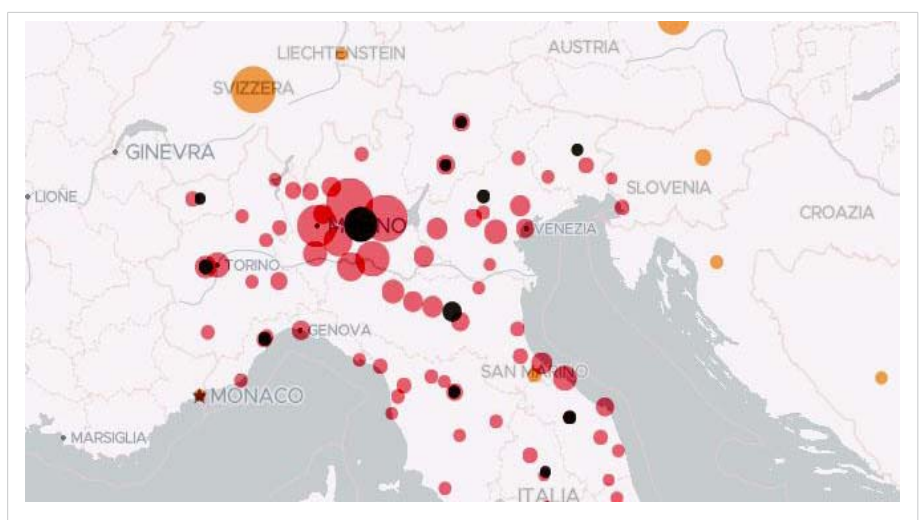

Figure 1: Diffusion of covid - 19 march 2020

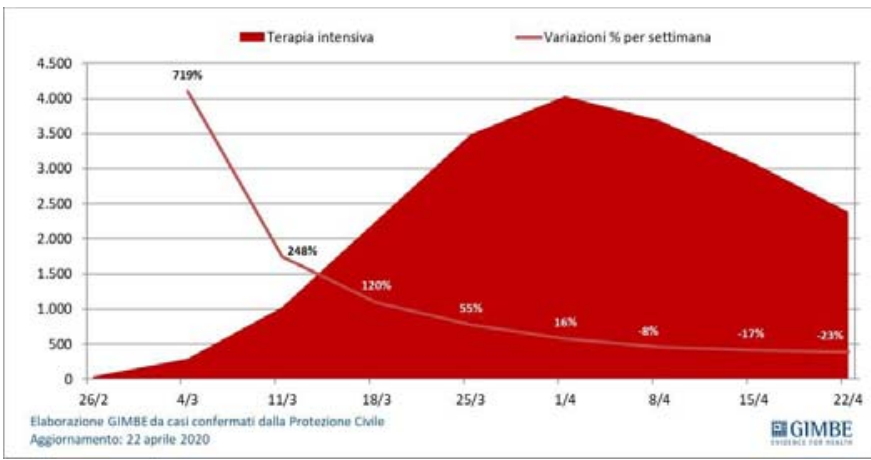

Figure 2: From Gimbe, confirmed cases italy 22 april 2020.

\section{Material and methods}

\section{Results}

From literature: According NEWSLETTER Gradazione alcolica: facciamo chiarezza! SIFAP 05 Maggio 2020:

"when we talk about it is fundamental to know if alchoolic -grade is expressed in Volume of alchool i in 100 Volume $(\mathrm{V} / \mathrm{V})$ o in weight of alhcool in 100 weight $(\mathrm{m} / \mathrm{m})$. The 2 value are not the same when added water to alchool due by a volumecontraction, in ex.alcohol $62,5 \%(\mathrm{~m} / \mathrm{m})\left(=62,5^{\circ}\right)$, will have a alcoholic grade $>$ if expressed in volume: $\mathrm{V} / \mathrm{V}$. So it is crucial in some igiene products that the alcoholic- grade is celarly expressed in weight or in volume.

See also the Ministry of health comunication regarding alcohol-solution and needed concentration: 70 or 75 grades" [1,2]. According article COVID-19 Pandemic and the Management- Strategy for Business and Economy:

"Relevant in this the diagnostic- availability, ICU beds, right number of pulmonary- ventilator, availability of
DRUGS (also experimental trial) and DPI- medical devices, disinfectants, oxygen and other" [3-5]. "Observing the results obtained in other kind of scientific or organizational -settings (military strategy, aereo-spatial Nuclear settings, insurances and other) is clear that introducing in day -by- day activity in emergency- settings makes possible to achieve the really best results. Using prospective instrument is the real tool to be added to the classic risk -analysis management procedure: the hystorical- data can not to be the only one- correct to be used.

So is strictly needed to share - translate the real good practice form a discipline (ex-insurance settings, industries, aereo-spatial and other kinds) to another (like emergencysettings). Multi-disciplinarity-(with the presence of clinical emergency pharmacist in medical team), sharing of knowledge, introducing the best -practice also if typical of other scientific discipline produces a good organization whit real useful results. In really Emergency situation only one failure in organizative- process can produce death of a patient so is crucial to adopt this Instrument also whit a prospectivepoint of view" [6].

\section{According SANTILLI}

"Hospital organization is fundamental to contain the diffusion o the - novel coronavirus. In an recent article published on Intesive Care -Medicine it was described SICHUAN PROVINCIAL. PEOPLES'S HOSPITAL during covid-19 epidemy. Doctor F. SANTILLI stating from this article analyzed some managerial and organizative hospital Aspects that in this epidemy could be crucial to overcome emergency" [7].

\section{According G. Kampf}

"Ethanol is used world-wide in the health-care facilities for hand- rubbing. It has been reported to have a stronger and broader kind of virucidal- activity compared with propanols. The aim of this review work was to describe the spectrum of virucidal- activity of ethanol in solution or as a commercially-available products. A systematic- research work was so conducted. Studies and works were selected when they contained original- data on reduction of viral. infectivity from suspension tests (about 49 studies) and contaminated- hands (17- studies). Ethanol at $80 \%$ was highly effective against all the 21 tested, enveloped- viruses within 30 s.

Murine - and adenovirus type 5 are usually inactivated by ethanol between $70 \%$ - $90 \%$ in 30 s whereas poliovirus type 1 was often found to be too resistant except for ethanol at $95 \%$ (all test viruses of EN-14476). Ethanol at 80\% is unlikely to be sufficiently effective against the polio-virus, calicivirus- (FCV), polyoma-virus, hepatitis A-virus (HAV) and foot-and-mouth disease virus- (FMDV). The spectrum of virucidal -activity of ethanol at $95 \%$, covers the majority of clinically relevantviruses. Additional acids can substantially improve the virucidal- activity of ethanol at lower- concentrations against, poliovirus, FCV, polyoma-virus and FMDV although selectedviruses such as HAV may still be too resistant. The selection of 
an suitable virucidal hand- rub should be based on the viruses most- prevalent in a unit and on the user -acceptability of the product under a frequent-use conditions" [8].

According WHO Guidelines on Hand Hygiene in Health Care: First Global Patient Safety Challenge Clean Care Is Safer Cre.WHO-recommended handrub formulations:

"Suggested composition of alcohol-based hand-scrub formulations for local production. The choice of components for the WHO-recommended hand-scrub- formulations takes into account cost- constraints and microbicidal -activity. The following 2 formulations are recommended for localproduction with a maximum of 50 litres per lot to ensure safety in the production and storage.

\section{Formulation I}

To produce a final concentrations of ethanol $80 \% \mathrm{v} / \mathrm{v}$, glycerol $1.45 \% \mathrm{v} / \mathrm{v}$, hydrogen- peroxide $\left(\mathrm{H}_{2} \mathrm{O}_{2}\right) \quad 0.125 \%$ $\mathrm{vol} / \mathrm{vol}$

Pour into a $1000 \mathrm{ml}$ graduated flask:

ethanol $96 \% \mathrm{v} / \mathrm{v}, 833.3 \mathrm{ml}$

$\mathrm{H}_{2} \mathrm{O}_{2} 3 \%, 41.7 \mathrm{ml}$

glycerol 98\%,14.5 ml

Top up the flask to $1000 \mathrm{cc}$ with distilled-water or water boiled and cooled; shake the flask gently to mix the content.

\section{Formulation II}

To produce a final -concentrations of isopropyl-alcohol $75 \% \mathrm{v} / \mathrm{v}$, glycerol $1.45 \% \mathrm{v} / \mathrm{v}$, hydrogen- peroxide $0.125 \%$ vol/vol:

Pour into a $1000 \mathrm{ml}$ graduated-flask:

Isopropyl- alcohol (with purity: 99.8\%), 751.5 cc

$\mathrm{H}_{2} \mathrm{O}_{2} 3 \%, 41.7 \mathrm{ml}$

glycerol 98\%, $14.5 \mathrm{ml}$

Top up the flask to $1000 \mathrm{cc}$ with distilled -water or water boiled and cooled; shake the flask gently to mix the content.

Only pharmacopoeial quality- reagents should be used (The International Pharmacopoeia) and not technical gradeproducts.

\section{Preparation}

The alcohol for the chosed-formulation is poured into a large- bottle or tank up to graduated- mark. $\mathrm{H}_{2} \mathrm{O}_{2}$ is added using the measuring -cylinder. Glycerol is added using a measuring - glass cylinder. As the glycerol is very- viscous and sticks to the walls of the measuring- cylinder, it can be rinsed with some sterile- distilled or cold- boiled water to be added and then emptied into a bottle-tank. The bottle/tank is then topped up to the corresponding mark of volume (10-litre or 50 -litre) to be prepared with the remainder of the distilled or cold, boiled- water.

The lid or the screw- cap is placed on the bottle/tank immediately after mixing to prevent the evaporation. The solution is mixed by gently shaking the recipient where appropriate (small- quantities), or by using a wooden, plastic or metallic- paddle. Electric mixers should not be used unless "EX" protected because of the danger of explosion. After mixing, the solution is immediately divided into smaller -containers $(1000,500$ or $100 \mathrm{ml}$ plastic- bottles). The bottles should be kept in quarantine for about 72 hours. This allows time for any spores present in the alcohol or the new or reused bottles to be eliminated by the $\mathrm{H}_{2} \mathrm{O}_{2}$.

\section{Quality control}

If the concentrated alcohol is obtained from localproduction, verify the alcohol -concentration and make the necessary adjustments in the volume to obtain the ending recommended -concentration. An alcohol-meter can be used to control the alcohol- concentration of the final- use solution; $\mathrm{H}_{2} \mathrm{O}_{2}$ concentration can be measured by titrimetry- (oxydoreduction reaction by iodine in acidic- environment ). A higher level quality control can be performed using gas chromategraphy and the titrimetric- method to control the alcohol and the hydrogen- peroxide content. the absence of microbial-contamination (including spores) can be checked by filtration, according to the EP European Pharmacopeia- specifications.

For more detailed -guidance on production and quality control of both -formulations, see the "WHO-recommended hand- antisepsis formulation - guide to local production" (Implementation -Toolkit available at http://www.who.int/ gpsc/en/).

\section{Labelling of the bottles}

The bottles should be labelled in accordance with nationalguidelines. Labels should include the following informations:

\section{Name of the institution}

Date of lab production and batch-number.

Composition: ethanol or isopropanol, glycerol and hydrogen peroxide ( $\% \mathrm{v} / \mathrm{v}$ can also be indicated) and the following statements:

WHO-recommended handrub-formulation For externaluse only Avoid contact with eyes Keep out of reach of children

Use: apply a palmful of alcohol-based hand-rub and cover all surfaces of the hands. Rub -hands until- dry. Flammable: keep away from the flame and the heat "[9].

"Alcohol -Disinfectant effectiveness in the ABHRs depends on 1) type of alcohol; 2) concentration; 3) quantity applied on 
hands; 4) time of exposure. Isopropanol, ethanol, n-propanol, or combinations of these alcohols are most commonly used in hand-- rubs. Unlike other antiseptics, these alcohols do not have the potential for acquired bacterial -resistance. None of these alcohols is effective against bacterial- spores.

When used at the same concentration, ethanol seems to have a lower bactericidal activity than propanols. Ethanol has superior viricidal- activity than propanols against nonenveloped viruses. Also, skin- tolerance is better with ethanol compared to n-propanol or isopropanol, thus ethanol is often the alcohol of choice in the ABHR -preparations. Ethanol concentrations of $60 \%-95 \%(\mathrm{v} / \mathrm{v})$ are deemed safe and effective for disinfection by the United States Food and Drug Administration, CDC and the WHO (Boyce et al., 2009, CDC, 2019a, FDA, U.S., 2020, FDA, U.S., 1994) including for use against SARS-CoV-2. Edmonds et al. suggested that the anti-microbial activity of the ABHRs is highly dependent on the choice of formulation (excipient) rather than on the concentration of alcohol. They suggested that the liquid, gel and foam-based products can all be equally effective if the ethanol content used was within the $60 \%$ - 95\% standard- range. increasing ethanolic concentrations of hand rubs from $80 \%$ to $85 \%$ $(\mathrm{v} / \mathrm{v})$ can reduce the contact time necessary to achieve an efficient bactericidal activity. the WHO, US FDA and CDC still maintain their recommendations of $60-95 \%$ ethanol content in ABHRs. An analysis of some currently marketed -products reveals indeed that ABHRs, sold in Italian- pharmacies as biocides, contain percentages of ethanol between $62 \%$ and $74 \%(\mathrm{w} / \mathrm{w}) /(70 \%$ to $80 \% \mathrm{v} / \mathrm{v})$. This goes in line with the standard- WHO, US FDA and CDC guidelines. It is worth highlighting that ethanol, unlike water, has a density $<1 \mathrm{~g} / \mathrm{cm} 3$, which means that percentages of ethanol in water by weight $(\mathrm{w} / \mathrm{w})$ and by volume $(\mathrm{v} / \mathrm{v})$ can be significantly different and must be specified on the label. A useful comparison between $\%$ by weight and by volume of ethanol in ABHRs is reported in a recently- published document- (BDC in 2020). Although this concept might seem trivial, there are cases of published works, where the concentration expression (either w/w or v/v) was not specified, as indicated by Kampf, ultimately presenting ambiguous- information. compounding and manufacturing, it is recommended to clearly specify the concentration- units of alcohol used in ABHRs" [10].

Related: Cleaning and disinfection of environmental -surfaces in the context of COVID-19: Interim guidance:

"The recommendation of $0.1 \%$ (1000 ppm) in the context of COVID-19 is a conservative- concentration that will inactivate the vast- majority of other pathogens that may be present in the health-care setting. However, for blood and body fluids large spills (- more than about $10 \mathrm{~mL}$ ) a concentration of $0.5 \%(5000 \mathrm{ppm})$ is recommended. Hypo-chlorite is rapidly inactivated in the presence of organic- material; therefore, regardless of the concentration used, it is important to first clean surfaces thoroughly with soap and water or detergent using mechanical -action such as scrubbing or friction. Highconcentrations of chlorine can lead to corrosion of metal and irritation of skin or mucous- membrane, in addition to potential side-effects related to chlorine-smell for vulnerable people such as people with asthma [11-17] and according: Coronavirus disease (COVID-19).

Situation Report - 115 .

Data as received by WHO from national authorities by 10:00 CEST, 14 May 2020.

"In healthcare- settings, environmental- surfaces include the surfaces of furniture and other fixed items (tables, chairs, walls, light switches, computer- peripherals) as well as the surfaces of non-critical medical equipment (equipment that only comes into contact with intact- skin, such as blood pressure- cuffs, wheel-chairs, incubators).

These surfaces should be frequently cleaned with water and detergent and followed by application of disinfectants-. Among the most common disinfectants used which have been demonstrated to be effective against SARS-CoV-2 are: ethanol $70 \%$ - 90\%; chlorine-based products (hypochlorite) at $0.1 \%$ (1000 ppm) for general environmental- disinfection or $0.5 \%$ (5000 ppm) for blood and body fluids large- spills; or hydrogen peroxide $>0.5 \%$. 5-6. The minimal time recommended of exposition.

to the surface for these disinfectants is 1 minute or according to the manufacturer-instructions. In non-healthcare settings, environmental surfaces include furniture and other fixed-items, such as counter tops, stairway -rails, as well as floors and walls. Disinfectants should be applied to high- touch surfaces to 7reduce potential SARS-CoV-2 contamination in community settings where the risk of contamination is unknown (gyms, offices, restaurants, accommodation sector and other) as well as in households and non-traditional facilities where individuals with suspected or confirmed COVID-19 disease are accommodated" [18].

"The World Health Organization ethanol-based handrub -(EBHR) formulation contains $1.45 \%$ glycerol as an emollient to protect healthcare- workers' (HCWs) -skin against dryness and dermatitis. However, glycerol seems to negatively affect the antimicrobial-efficacy power of alcohols. the minimal concentration of glycerol required to protect- hands remain unknown. We aim to evaluate the tolerance of HCWs to the WHO EBHR formulation using different concentrations of glycerol in a tropical climate healthcare -setting. In a tropical climate setting, the WHO-modified EBH-R formulation containing $0.5 \%$ glycerol led to better ratings of skin- tolerance than the original formulation, and, may offer the best balance between skin- tolerance and antimicrobial efficacy" [19].

\section{Practical experience}

LOCATION- place of observation: PC AREA about 700 beds, 6 hospital (presidium)(but also territorial need). 
Time of observation: from 1 march to 15 may 2020. Hospital pharmacist involved in galenic lab: Two hospital pharmacist manager and 1 pharmacist (about 1 pharmacist by day) Organization of work: under director of hospital pharmacy and responsible of galenic non sterile lab. The need of disinfectants and antiseptics for this hospital was verified by HOSPITAL PHARMACIST director, MEDICAL DEVICED responsible and other manager also from HEALTH CENTRAL OFFICE OF THE HOSPITAL. The formulation adopted was the WHO formula, and approved by infectious disease physicians director (also under the responsability of the pharmacist manager of lab. Galenic and director chief pharmacist of hospital).

\section{Procedure}

According the ones in use in galenic lab, and according FU XII ED , EP ed other normative rules.

\section{Product produced}

According to the WHO FORMULA and other industrial products:

1) hand disinfectant alchoolic gel composition: Ethanol $96 \% \mathrm{v} / \mathrm{v} 623 \mathrm{ml}$ hydroxi-etilcellulose $10 \mathrm{gr}$ and depurated water q.b. $1000 \mathrm{ml}$.

2) hand-alchoolic solution disinfectant composition: ethanol 96\% 833,3 $\mathrm{ml}$ hydrogen peroxide 3\% 41,7 $\mathrm{ml}$, glicerol farmacopeia official $98 \% \quad 14,5 \mathrm{ml}$ and depurated water since $1000 \mathrm{ml}$.

3) alcool 70- 75 grades solution: Composition alchool etilic $96 \%$ denaturated $733 \mathrm{ml}$ since $1000 \mathrm{ml}$ with depurated water.

4) amuchine hand solution: from industrial products divided in bottle of $500 \mathrm{ml}$.

\section{Raw materials}

Ethanol alcool 94\% - 99\%

Glicerolo 98\% FU

Hydrogen peroxide 3\%

Depurated water

Hydroxietilcellulosa

Containers, Bottles, Dispenser and other closing system.

Calibrated LAB GLASSWARE: to measure accurate volume, becker, bottleneck and other necessary Amounts produced: according the daily working schedule signed.

Medium week production: approximately 600 flac.da 500 $\mathrm{ml}$ of hand disinfectant (periods emergency COVID-19).

$600 \times 500 \mathrm{ml}=300.000 \mathrm{ml}$ for week
Product: Medium production level by week

1) Alcoholic gel (400 flac. for week)

2) Amuchina $\mathrm{x}$ - germ (200 flac for week)

Period of observation: March - may 2020 Figures 3,4

\section{Management of the system of production:}

- Rapid supply chain systems of raw material and bottles from producers

- Verify of real availability from different providers

- Costs analysis, benchmark

- Emergency need.

- Clinical need: high need of disinfections procedures dues to severe pandemia level

- High amount of production to cover hospital and territorial need

DPI used: musk FFP2, sterile gloves, caps, Lab coats, protective glasses (all single use).

Ordering procedure: BUYING OFFICE inside hospital , after enconding and cost evaluation.

The effective availability was verified from different providers in order to be sure of the products supply.

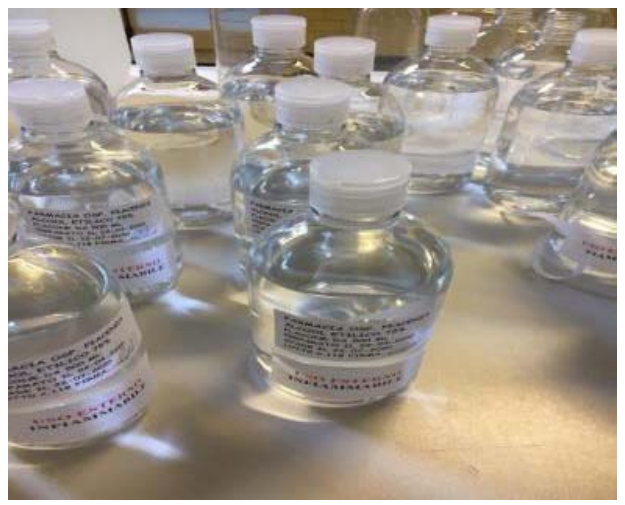

Figure 3: Bottles of disinfectants produced in hospital by galenic lab. PC AREA.

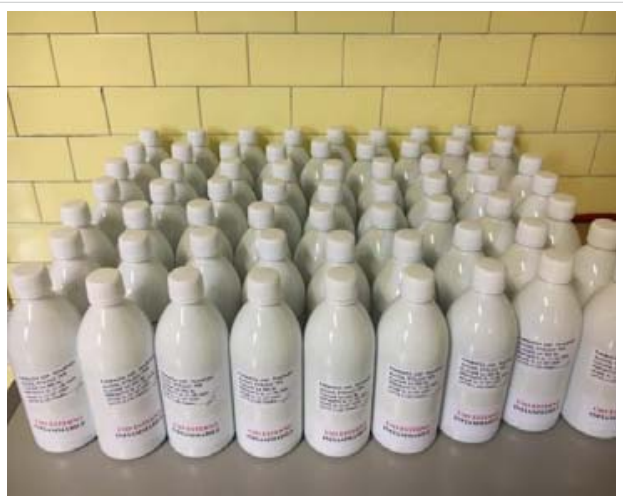

Figure 4: Production of disinfectant by hospital galenic lab. 


\section{Practical procedure}

Due to the high amount of raw material was needed a special system to bring this high amount of raw material into the galenic lab. Before to start was needed to put on

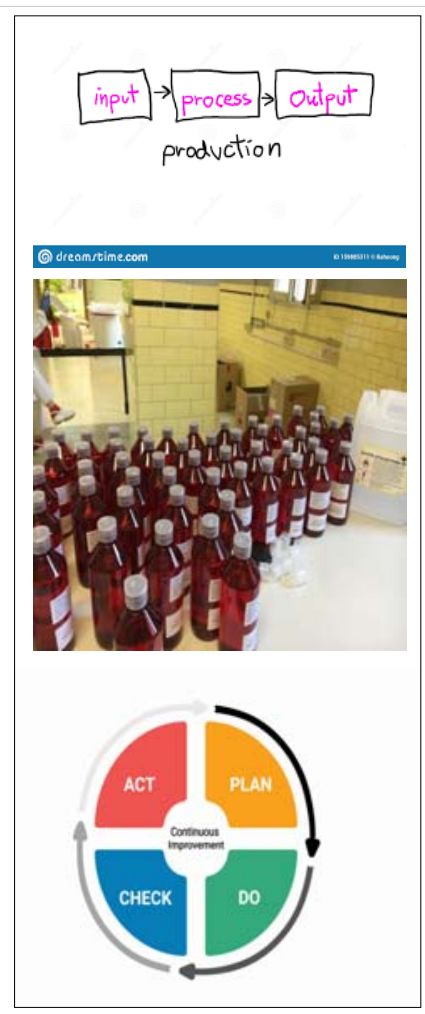

gloves, protections DPI, and others according to safety rules to protect pharmacists but also the product from any kind of contamination, according to the pharmacopeia in use. Right LABELING according safety international rules (CLP REGOL): name of the galenic product and added risk logo (HAZARD)

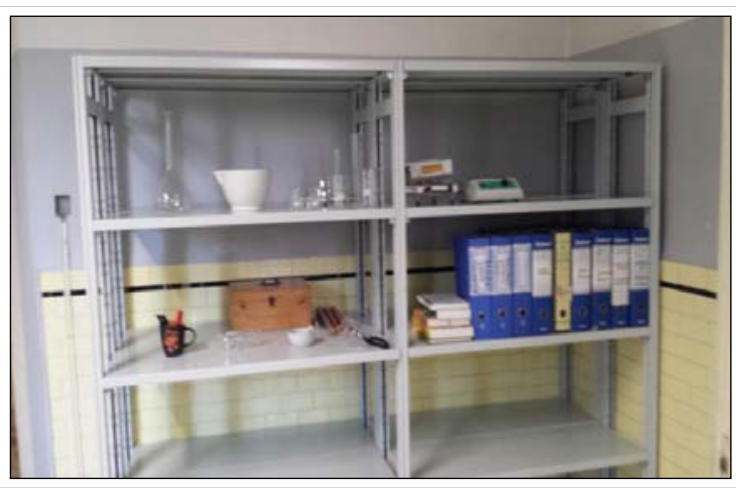

and prudence phrases. An advice of usage, date of expiry, name of the pharmacy.

Label: Shake before use.

General conservation suggestion: not near heat source Pay attention product based on alchool are easily flamable.

\section{Expiration data:}

2 month for hand alcholic gel and 3 month for ethanol 75\%.

At the end the pharmacist writes working document and then after the control signes this. Then an evaluation of global costs was performed: raw material, bottles, and any other products used in order to have a cost by 1 bottle of $500 \mathrm{ml}$ to be compared with industries products. To obtain right price was used the official formulary of pharmacist in Italy with cost for kind of products. Risk analisys: Chemical risk and biological risk.

All raw materials: According risk schedule and technical resume. (according the various galenic).

In example:

vAlcool etilic: inflamable

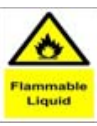

Alcool denaturate: NOCIVO - HARMFUL

Biological risk: According pharmacopeia rules for this kind of galenic production.

Expiration data: 60-90 days according the kind of galenic product All pharmacists was correctly trained to all kind of procedure used, according to the preventing risk rules and quality management policy by the chief of laboratory.

Quality control: After all daily production batches, was performed quality control according to pharmacopeia need.

- $\quad$ Correct Procedure

- $\quad$ General Aspect

- Verify Of The Closing System

- Number Of Preparation By Single Lot

- $\quad$ Labeling Correct

- $\quad$ Sign of The Pharmacist on Schede of Preparation and on Label

\section{Economic evaluation}

From industry: Alcool 70\% : about 1,2 euro for 1 liter CENTRAL BUYING CENTRE $(3,5$ euro/500 $\mathrm{ml}$ in commerce out

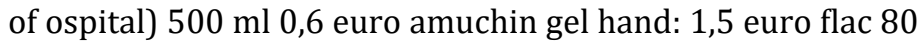
$\mathrm{ml}$ and 2,3 euros for bottle of $500 \mathrm{ml}$ septaman gel hand 100

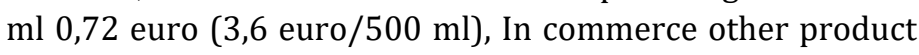
about 6 EURO/500 ML.

\section{Our production}

Alcol ethylic 75\% flac $500 \mathrm{ml}: 2,5$ euro ( raw material not easily available form commerce).

Alcoholic hand gel flac $500 \mathrm{ml}$ : 5,23 euro.

Alcoholic hand solution solution flac $500 \mathrm{ml}$ : 7,43 euro.

Amuchine gel hand product from dividing procedure (of tanks 5 LT). 
Costs: Alcool 75\% $500 \mathrm{ml}$ : 2,50 (galenic lab) -0,6 euro ( industry) $=+1,45$ euro /falc $500 \mathrm{ml}$ (internal galenic products)

Alchoolic hand gel $500 \mathrm{ml}$ : 7,34 euro (galenic lab) -3,6 euro $=3,74$ flac $500 \mathrm{ml}$.

Raw material PRICE - COSTS:

ALCOOL ETILICO FU 96\% LT.1 FLAC 15 euro Deputared water acef: 2,55 euro x $5 \mathrm{lt}$

\section{ALCOOL ETILICO 94 GRADES DEN 4 LITERS 20 EURO}

GLICEROLO FU 1 L 9,50 EURO LITER

IDROSSIPROPIL METILCELLULOSA 1KG 30 EURO

$\mathrm{H}_{2} \mathrm{O}_{2} 3 \% 100$ ML 2 EURO

\section{COST OF AMUCHIN GEL HAND 5 LT: 19,5 euros}

- Bottle PET white lucido o trasparente da $100 \mathrm{ml}$ PFP100B-02: costs $€ 0,152 \mathrm{~cd} /$ flacone -Capsula con sigillo e riduttore preinserito PCP00742: cost $€ 0,050$ cd/capsula

- Tappo flip top neutro 28/410 foro $3 \mathrm{~mm}$ : cost $€ 0,060$ cd/tappo

- Flacone PET trasparente da $500 \mathrm{ml}$ PFL500D-00: cost $0,330 \mathrm{~cd} /$ flacone

- Pompa dispenser bianca 28/410 x flacone PFL500D-00: $€ 0,2203 \mathrm{~cd} /$ dispenser

\section{Total units costs}

Medium week production: about

600 flaconi da $500 \mathrm{ml}$ di hand disinfectant (periods emergency COVID-19).

$600 \times 500 \mathrm{ml}=300.000 \mathrm{ml} \mathrm{WEEK}$

Products: Medium production level by week

1) Gel alcolico (400 flac. A settimana)

2) Amuchina x- germ (200 flac a settimana) travasata da taniche da 5 litri.

\section{Registration of production data}

All disinfectant manifactured in lab. Galenic was registerd in official way for PHARMACOPEIA need, normative rules, quality procedure and to make possible aslo recall if needed.

Registration of Adr: in the period observed no any ADR adverse event reaction related galenic lab disinfectants produced was registered in official way (FV office report) No reported any official skin reaction or other adverse reaction for all production in local lab. Recall of product: No one registered in the period observed.
Distribution of Product: All product prepared in galenic lab as disinfectants was distributed or inside hospital (covid - ward or other ) or outside hospital for territorial health use.

Formative program: In the same period during the internal production of disinfectatns was performed an UPDATING formative program related galenic activity to the new pharmacist of the Hospital assigned.

Economic evaluation by hospital central buying office: NO any official communication of non conformity sended to the hospital pharmacist.

\section{Discussion}

Before to start this section it is interesting to see the Formulations WHO OMS as useful instruments:

\section{Formulation I}

To produce final concentrations of ethanol $80 \% \mathrm{v} / \mathrm{v}$, glycerol $1.45 \% \mathrm{v} / \mathrm{v}$, hydrogen peroxide $\left(\mathrm{H}_{2} \mathrm{O}_{2}\right) 0.125 \% \mathrm{v} / \mathrm{v}$.

Pour into a $1000 \mathrm{ml}$ graduated flask:

a. ethanol $96 \% v / v, 833.3 \mathrm{ml}$

b. $\mathrm{H}_{2} \mathrm{O}_{2} 3 \%, 41.7 \mathrm{ml}$

c. glycerol $98 \%, 14.5 \mathrm{ml}$

Top up the flask to $1000 \mathrm{ml}$ with distilled water or water that has been boiled and cooled; shake the flask gently to mix the content.

\section{Formulation II}

To produce final concentrations of isopropyl alcohol $75 \% \mathrm{v} / \mathrm{v}$, glycerol $1.45 \% \mathrm{v} / \mathrm{v}$, hydrogen peroxide $0.125 \% \mathrm{v} / \mathrm{v}$ :

Pour into a $1000 \mathrm{ml}$ graduated flask:

a. isopropyl alcohol (with a purity of 99.8\%), $751.5 \mathrm{ml}$

b. $\mathrm{H}_{2} \mathrm{O}_{2} 3 \%, 41.7 \mathrm{ml}$

c. glycerol $98 \%, 14.5 \mathrm{ml}$

Top up the flask to $1000 \mathrm{ml}$ with distilled water or water that has been boiled and cooled; shake the flask gently to mix the content.

According WHO recommended handrub formulations:

12.1.4: EFFICACY it is the consensus opinion of ther WHO expert group that the WHO recommended handrub formulations can be used both for hygienic hand antisepsis and for presurgical hand preparation.

Production and storage: According formula used, pharmacopeia and other rules.

WHO - recommended handrub formulations: Safety standards: 12.1 .5 
Whit regards to skin reactions, handrubbing with alcohol -based products is better tolerated than handwashing whit soap and water. In a recent study conducted among ICU HWs, the short-term skin tolerability and acceptability higher then those of a reference product. COVID-19 Mortality rate in Pc hospital was zero in 10 may, and an high mortality' rate due by Coronavirus In PC area was registered in period from march to may (like in other city like lodi, Cremona, Brescia, Parma, Alessandria).

Cumulative mortality: Piacenza (258,5 death x 100.000 person living in the area). The COVID-19 emergency showed clearly the need in pandemia situation of galenic hospital laboratory whit high productivity to guarantee the high amount il little time to control diffusion of disease. Al this show that corrected meausre was introduced: And also in field of disifectants use. The same the figure of galenic hospital pharmacist is fundamental. The global safety of galenic products come from FARMACOPEIA RULES and all normatives of lab galenic added to the formulary adopted (WHO formula). So we can assume equal safety of industrial products for the same pathology need.

A last consideration: A good management system of laboratory make possible to do it.

Related the costs of this production it is needed to explaining that in this period the global amount of disinfectant by industry was reduced using galenic production. The high amount of raw material not used for the acute time of pandemia can be used next. The total cost take in consideration: time of pharmacist, raw material, bottle costs, fixed cost of laboratory In the observed period was reduced the amount of product form industry and the stokes of raw material will be used in the next 6 month- 1 year.

\section{Conclusion}

As Observed mortality was highly reduced after 2-3 month after the start in PC AREA, this mean that a complexive number of death of about 900-1000 death becomes about zero in first day of march. This mean that all measure introduced where correct, and also the disinfectants and antiseptic policy adopted (of industrial origin or by internal hospital galenic laboratory production).

The results of this literature review added to the result of our practical experience show that the hospital galenic laboratory play a crucial role in emergencies like COVID-19 pandemia. In this situation we have see in march 2020 pharmaceutical industry was not able to produce the right amount of disinfectants and antiseptic for the need of some hospital in red zone. In this situation the high performance of hospital pharmacy organization make possible an efficacy responce and to achieve great clinical outcomes. Disinfectants are products that make possible to control infectious disease in hospital setting and other assimilated structure, protect healthcare professionals and patients in the same way.
Hand washing and antiseptic procedure, disinfection of surfaces, and of medical devices and other Instrument was into the main preventive and contro-measure. High production added to limited time of responce was the keyword. The same it was relevant also the buying procedure to buy in few days all raw material to produce this. In period march 2020 was also needed to produce disinfectants not only for INTERNAL HOSPITAL but also to the TERRITORIAL need (basis phisicians ambulatory of all province).

As conclusion of this work is possible to say that hospital galenic laboratory and the managerial abilities of hospital pharmacist contribute in high way to the global result. This experience was obtained in an advanced countries but it can be exported also in other situation to cover the need of disinfectants and antiseptic. What is relevant is that an approach like WHAT IF ANALISYS in prospectic way can help in DISASTER EMERGENCY like pandemia situation. The internal galenic lab production was a winning strategy in this emergencial event and contribute to the global result. The ability to adapt to the new situation is a great instrument to be used as common way of work.

\section{References}

1. Vademecum per il farmacista che lavora in un laboratorio galenico. SIFO. 2017.

2. https://www.sifap.org/newsletter/gradazione-alcolica-facciamochiarezza

3. Farmacopea Ufficiale XII ED. - TABELLA 6 Apparecchi ed utensili obbligatori in farmacia.

4. SIFAP Societa' Italiana Farmacisti Preparatori - POSITION PAPER 2015: Formule Magistrali

5. Luisetto M, Latyshev YO. Covid -19 Pandemic and the Management Strategy for Business and Economy. J Econ Bus Stud. 2020; 3: 153.

6. Luisetto M. Risk Analysis, Vision Zero Approach, Safety Accident Report, what if Analysis as New Instrument in Emergency Medicine and Pharmacy. EC Emergency Medicine and Critical Care. 2019; 3: 01-02.

7. https://www.esanum.it/today/posts/per-contrastare-lepidemia-ci-vuoleorganizzazione 5 march 2020

8. Efficacy of ethanol against viruses in hand disinfection G. Kampf $J$ Hospital Infect. 2018; 98: 331-e338

9. WHO Guidelines on Hand Hygiene in Health Care: First Global Patient Safety Challenge Clean Care Is Safer Care. WHO-recommended handrub formulations. Int J Pharm 2020; 584: 119431.

10. Berardi A, Perinelli DR, Merchant HA, Bisharat L, Basheti IA, et al. Hand sanitisers amid COVID-19: A critical review of alcohol-based products on the market and formulation approaches to respond to increasing demand. Int J Pharm. 2020; 584: 119431.

PubMed: https://pubmed.ncbi.nlm.nih.gov/32461194/

11. ITALIAN OFFICIAL PHARMACOPEA XII ED.

12. European pharmacopeia.

13. Internal procudere hospital galenic production.

14. D.lgs $81 / 2008$ e Dlgs n.106/2009, Dlgs n. 626/94.

15. Regolamento n. 1907/06 CE REGOLAMENTO REACH.

16. regolamento CE N. 1272/2008 Gazzetta UE 31 dec 2008. 
17. Cleaning and disinfection of environmental surfaces in the context of COVID-19 Interim guidance. 2020

18. Coronavirus disease (COVID-19) Situation Report - 115Data as received by WHO from national authorities by 10:00 CEST, 2020.

19. Menegueti MG, Laus AM, Ciol MA, Auxiliadora-Martins M, BasileFilho $\mathrm{A}$, et al. Glycerol content within the WHO ethanol-based handrub formulation: balancing tolerability with antimicrobial efficacy. Antimicrobial Resistance \& Infection Control. 2019; 8: 109.
20. Part I. Review of scientific data related to hand hygiene cap 12 whorecommended hand rub formulations

21. Luisetto M. Biocidi e disinfettanti per ambienti, aria e superfici. Nuove tecnologie e normative. 2020.

22. Luisetto M. Course in Biosecurity and sanification technicians. Unitelma la sapienza - saint george school lessons biocidi- reserved courses. 2020. 